\title{
The Measurement of Void Fraction in Beds of Granulated Iron Ore Sinter Feed*
}

\author{
By W.J. RANKIN** and P. W. ROLLER ${ }^{* * *}$
}

\begin{abstract}
Synopsis
Iron ore sinter feeds are granulated with water to improve permeability of the bed during sintering. The permeability of a packed bed is a complex function of the effective mean diameter of the granules and the void fraction of the bed.

This paper describes a lechnique for measuring the void fraction of a bed of granulated iron ore sinter feed by filling the voids, under vacuum with kerosene. Kerosene, being immiscible with water, does not penetrate the moist granules.

For the hematite ore sludied, bed void fraction increased initially as the amount of water used for granulation was increased. This was due most likely to the narrowing of the size distribution of the granules. A maximum void fraction of 0.49 occurred at about $5.3 \%$ water. Thereafter, additional water used for granulation resulted in a decrease in bed void fraction due probably to slumping of the granules as they were packed to form a bed.

Bulk density measurements on the granulated mixes confirmed the shape of the voidage vs. moisture content relation obtained by kerosene displacement and a satisfactory matching of void fraction values by the two methods was obtained using a value of $4.08 \mathrm{~g} / \mathrm{cm}^{3}$ for the density of dry sinter feed. This value agreed favourably with the experimentally determined value of $4.03 \mathrm{~g} / \mathrm{cm}^{3}$ and suggests, for the sinter feed studied, all the internal porosity of granules is filled with water.
\end{abstract}

\section{Introduction}

To produce sinter, fines or concentrates are mixed with coke breeze, flux, undersize sinter and iron rich, in-plant products. Water is added and the mix is tumbled. This process, known as granulation, coats the finer material onto the coarser material resulting in a coarser and more uniformly sized material. ${ }^{1)}$ The mix is then spread in a uniform layer on a moving grate, down draught suction is applied and coke at the top of the bed is ignited. A narrow zone of burning coke (the flame front) moves downward through the bed producing, among other phenomena, localized melting. On resolidification of the melt, agglomeration of the coarser, unmelted material occurs.

Voice and Wild ${ }^{2-5}$ ) showed that the air requirement for sintering is determined by heat transfer requirements rather than fuel combustion requirements and the velocity of the heat front, therefore, depends on the ability of the bed to pass air and gaseous reaction products; i.e., on the bed permeability. The relation between flow rate and the applied suction in a packed bed is provided by the Ergun equation ${ }^{(6)}$ :

$$
\frac{\Delta p}{l}=\frac{150 \eta V_{0}(1-\varepsilon)^{2}}{d_{p}^{2} \varepsilon^{3}}+\frac{1.75 \rho V_{0}^{2}(1-\varepsilon)}{d_{p} \varepsilon^{3}}
$$

where, $\Delta p:$ the applied suction $(\mathrm{Pa})$

$l:$ the bed height $(\mathrm{m})$

$\eta$ : the viscosity of the gas $(\mathrm{kg} / \mathrm{m} / \mathrm{s})$

$V_{0}:$ the superficial gas velocity $(\mathrm{m} / \mathrm{s})$

$\varepsilon:$ the void fraction in the bed (-)

$\rho$ : the density of the gas $\left(\mathrm{kg} / \mathrm{m}^{3}\right)$

$d_{p}$ : the effective mean diameter of the granulated feed $(\mathrm{m})$.

For a particular value of $\Delta p / l$, the flow rate is a complex function of the effective particle diameter and void fraction of the granulated mix (for constant viscosity and density of gas).

The application of the Ergun equation to sinter feeds containing Australian ores has been described elsewhere. ${ }^{7)}$ In that study the Ergun equation was applied to three different iron ores to determine the variation of the shape factor of granulated sinter feeds and of void fraction down packed beds of granulated feeds, both as a function of the moisture content. It is thought that these parameters may be related to the resistance of sinter mixes to slumping due to condensation and that the Ergun equation may be useful in assessing the sintering potential of ore blends.

A technique developed to measure the size distribution and mean diameter of granulated sinter mixes has been described previously. ${ }^{1)}$ Briefly, the procedure is to shake a representative sample of about $500 \mathrm{~g}$ of moist, granulated sinter feed into a vessel containing sufficient liquid nitrogen to freeze the granules (quasi-particles). The granules may then be screened without degradation using a laboratory sieve shaker to obtain their size distribution. The purpose of this paper is to describe the complementary technique for measuring void fraction of a sinter mix, for use in the Ergun equation, and to ascertain the effect of moisture content on the void fraction for a particular ore type.

\section{Experimental Procedure}

An Australian porous hematite ore consisting of polycrystalline hematite and bladed secondary hematite was used for the experiments. This ore was described as Type $B$ in previous papers. ${ }^{1,7)}$ Ore fines were blended with $7 \%$ coke ( $<6 \mathrm{~mm}), 37.5 \%$ return sinter (both on an ore basis) and limestone $(<3 \mathrm{~mm})$ to give a $\mathrm{CaO} / \mathrm{SiO}_{2}$ ratio of 1.8 . For development tests, $120 \mathrm{~kg}$ batches of mix were granulated in a pilot plant scale paddle mixer followed by

* Manuscript received on October 8, 1984; Accepted in the final form on April 11, 1985. C 1985 ISIJ

** CSIRO, Australia ; presently Visiting Associate Professor, Department of Chemical Engineering, University of Waterloo, Ontario, Canada N2L 3GI

*** Central Research Laboratories, Broken Hill Proprietary Co., Ltd., Shortland, N.S.W., Australia. 
a pass through a granulating drum. For the laboratory tests to ascertain the effect of moisture level on the void fraction of mix, a large batch of dry mix was split into $10 \mathrm{~kg}$ sub-samples. The individual $10 \mathrm{~kg}$ batches were mixed in a laboratory paddle mixer for $1 \mathrm{~min}$, water was added and mixing continued for a further $5 \mathrm{~min}$, after which steady state granulation existed.

For void fraction determinations, a representative sub-sample was taken on a steel scoop which was then held just above the top of a $1 l$ glass beaker. The scoop was shaken gently in a sideways motion to dislodge individual granules of feed which fell into the beaker. When the beaker was filled, a straight edge was drawn across the rim to remove the excess material without compacting the remainder. The beaker and contents were then weighed. Knowing the mass of the empty beaker and its volume $(1 l)$, the bulk density of the granulated material was calculated. This result provides a measure of the void fraction provided the granule density is known or estimated.

A second measure of void fraction was obtained by filling the void space in the beaker with kerosene. The increase in mass of the beaker due to the addition of kerosene relative to the increase in mass on filling the empty beaker with kerosene gave the void fraction in the bed. Kerosene was selected from several liquids tested because (i) being immiscible with water it does not penetrate the moist granules and fills only the free space between them, (ii) it has a relatively low viscosity and hence flows readily into the tortuous channels between the granules and (iii) not having an excessively high vapour pressure it does not volatilize to a significant extent during the time of the experiment, even when vacuum is applied.

After considerable trial and error, a method of kerosene addition was developed which gave fairly reproducible results. The major problem in adding the kerosene was to displace all the air from the void space. A second, lesser problem, was to add the kerosene in a manner which did not disturb the bed. The apparatus finally adopted is shown in Fig. 1. The sample in the beaker was placed in the vacuum dessicator with the kerosene inlet tube just touching the inside surface of the beaker. With valves $\mathrm{A}$ and B (Fig. 1) closed, the dessicator was then evacuated with a laboratory vacuum pump to an absolute pressure of $17 \mathrm{kPa}$. Valve $\mathrm{A}$ was released to allow a slow, gentle flow of kerosene into the beaker. The level of kerosene rose in the beaker and when the first drop of liquid flowed off the pouring lip valve A was closed. Atmospheric pressure in the dessicator was then gently restored by opening valve B slightly. This forced kerosene into any void space not already occupied and the level of kerosene in the beaker usually fell by a slight amount. This procedure was repeated until no further fall in the level occurred (usually after less than three repetitions). The beaker was then removed carefully and weighed.

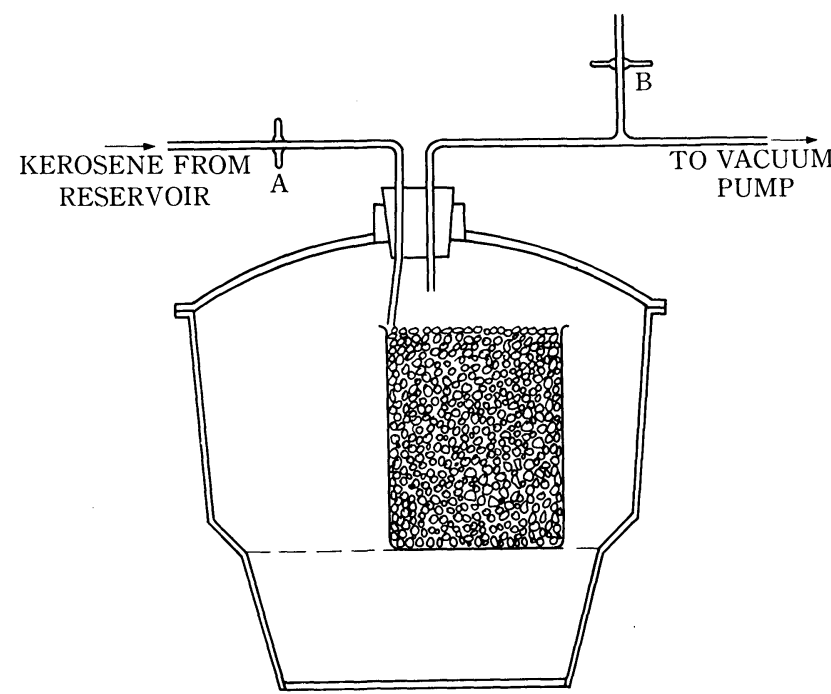

Fig. 1. Apparatus for filling the void space of a bed of sinter feed with kerosene.

Table 1. The effect of pressure on void fraction determination by kerosene displacement. (Samples granulated in pilot-scale mixer and granulating drum.)

\begin{tabular}{|c|c|c|c|c|}
\hline \multirow{2}{*}{$\begin{array}{l}\text { Air } \\
\text { pressure } \\
\text { in the } \\
\text { dessicator } \\
(\mathrm{kPa})\end{array}$} & \multicolumn{2}{|c|}{$\begin{array}{c}\text { Sample 1 } \\
5.52 \% \text { moisture } \\
\text { (Moist basis) } \\
\text { void fraction (-) }\end{array}$} & \multicolumn{2}{|c|}{$\begin{array}{c}\text { Sample } 2 \\
6.98 \% \text { moisture } \\
\text { (Moist basis) } \\
\text { void fraction (-) }\end{array}$} \\
\hline & $\begin{array}{l}\text { After 1st } \\
\text { filling }\end{array}$ & $\begin{array}{l}\text { After final } \\
\text { filling }\end{array}$ & $\begin{array}{l}\text { After 1st } \\
\text { filling }\end{array}$ & $\begin{array}{l}\text { After final } \\
\text { filling }\end{array}$ \\
\hline 17 & 0.454 & 0.454 & 0.448 & 0.461 \\
\hline 17 & 0.446 & 0.443 & 0.448 & 0.462 \\
\hline 17 & 0.445 & 0.449 & 0.437 & 0.457 \\
\hline 34 & 0.442 & 0.442 & 0.455 & 0.463 \\
\hline 67 & $(0.429)$ & $(0.429)$ & 0.450 & 0.456 \\
\hline 84 & 0.452 & 0.451 & $(0.473)$ & $(0.473)$ \\
\hline Average & 0.448 & 0.448 & 0.448 & 0.460 \\
\hline $\begin{array}{l}\text { Standard } \\
\text { deviation }\end{array}$ & 0.005 & 0.005 & 0.007 & 0.003 \\
\hline
\end{tabular}

\section{Results}

\section{Reproducibility of Results Using Kerosene Displace- ment Technique}

Two large batches of mix were granulated at different moisture levels. Six beaker-samples were taken from each granulated batch and filled with kerosene after evacuating to different pressures. The results are summarized in Table 1.

The technique gave quite reproducible values at all the pressures. The change in value of the void fraction between the first and final filling was quite small and this is taken as evidence that water was not forced into the granules thereby falsely increasing the value of void fraction.

\section{Comparison between Kerosene Displacement Technique and Bulk Density Measurement Technique}

A series of granulation tests was performed on $10 \mathrm{~kg}$ samples over a range of moisture contents. 
The results of these tests are presented in Table 2. The void fraction measured by kerosene displacement shows a consistent trend with moisture level of the mix. This is shown in Fig. 2, the curve being drawn to fit these values. The void fraction first rises with increasing moisture content to a maximum of about 0.49 at about $5.3 \%$ moisture then decreases at higher moisture levels.

Void fraction $(\varepsilon)$ is related to bulk density by the

Table 2. Results of experiments to determine the effect of moisture content on void fraction of granulated sinter mixes by kerosene displacement and bulk density measurement.

(Samples granulated in laboratory mixer.)

\begin{tabular}{|c|c|c|c|c|}
\hline \multirow{2}{*}{$\begin{array}{c}\text { Moisture } \\
\text { in quasi- } \\
\text { particles } \\
\text { (\%) (Moist } \\
\text { basis) }\end{array}$} & \multirow{2}{*}{$\begin{array}{c}\text { Void } \\
\text { fraction } \\
(-) \\
\text { (Kerosene } \\
\text { method) }\end{array}$} & \multirow{2}{*}{ 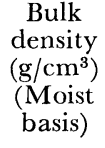 } & \multicolumn{2}{|c|}{$\begin{array}{c}\text { Void fraction } \\
\text { (from bulk density) }\end{array}$} \\
\hline & & & $\begin{array}{l}\rho_{0}=4.08 \\
\mathrm{~g} / \mathrm{cm}^{3 *}\end{array}$ & $\begin{array}{l}\rho_{0}=4.03 \\
\mathrm{~g} / \mathrm{cm}^{3 * *}\end{array}$ \\
\hline 2.60 & 0.430 & 2.225 & 0.411 & 0.404 \\
\hline 3.95 & 0.486 & 1.883 & 0.482 & 0.477 \\
\hline 4.50 & 0.483 & 1.874 & 0.477 & 0.472 \\
\hline 5.90 & 0.486 & 1.817 & 0.474 & 0.469 \\
\hline 6.49 & 0.489 & 1.740 & 0.488 & 0.483 \\
\hline 6.80 & 0.469 & 1.795 & 0.468 & 0.463 \\
\hline 7.40 & 0.451 & 1.821 & 0.452 & 0.447 \\
\hline 7.61 & 0.454 & 1.803 & 0.455 & 0.449 \\
\hline 8.00 & 0.421 & 1.846 & 0.436 & 0.431 \\
\hline 8.34 & 0.424 & 1.862 & 0.427 & 0.421 \\
\hline 8.64 & 0.402 & 1.912 & 0.407 & 0.401 \\
\hline 10.1 & 0.332 & 2.040 & 0.345 & 0.339 \\
\hline
\end{tabular}

* The true density of dry mix required to obtain a match of the void fractions determined by kerosene displacement and the bulk density measurement.

** The value of true density calculates using mass percent and true densities of raw materials. relation

$$
\varepsilon=1-\frac{\text { Bulk density of the mix }\left(\mathrm{g} / \mathrm{cm}^{3}\right)}{\text { Density of the granules }\left(\mathrm{g} / \mathrm{cm}^{3}\right)}
$$

The density of granules depends on the density of the solids comprising them, and the amount of water in the granules. The density of the moist granules is related to the density of dry sinter feed as follows:

$$
\text { Density of granules }=\frac{100}{\frac{100-w}{\rho_{0}}+\frac{w}{\rho_{w}}}
$$

where, $w$ : the mass percent of moisture in the granules (moist basis)

$\rho_{0}:$ the density $\left(\mathrm{g} / \mathrm{cm}^{3}\right)$ of the dry sinter feed not including the internal porosity of the grains

$\rho_{w}:$ the density of water $\left(=1 \mathrm{~g} / \mathrm{cm}^{3}\right)$.

In the derivation of this equation it is assumed that all internal pores in the raw materials are filled with water and that excess water occupies the pores between the grains of raw material within the quasiparticles. The derivation of Eq. (3) is given in Appendix.

A value of $\rho_{0}$ was used such that a satisfactory match between the two voidage measurements was obtained at one moisture level. The level of $6.80 \%$ moisture was used since there are approximately the same number of measurements below this level (5) as there are above it (6). The value of $\rho_{0}$ to obtain a match was $4.08 \mathrm{~g} / \mathrm{cm}$. Then, using this value in conjunction with Eqs. (2) and (3) void fractions were calculated at all other moisture levels. These values are given in Table 2 and are shown in Fig. 2 to permit comparison with the values obtained by kerosene displacement. As may be seen the agreement is very good.

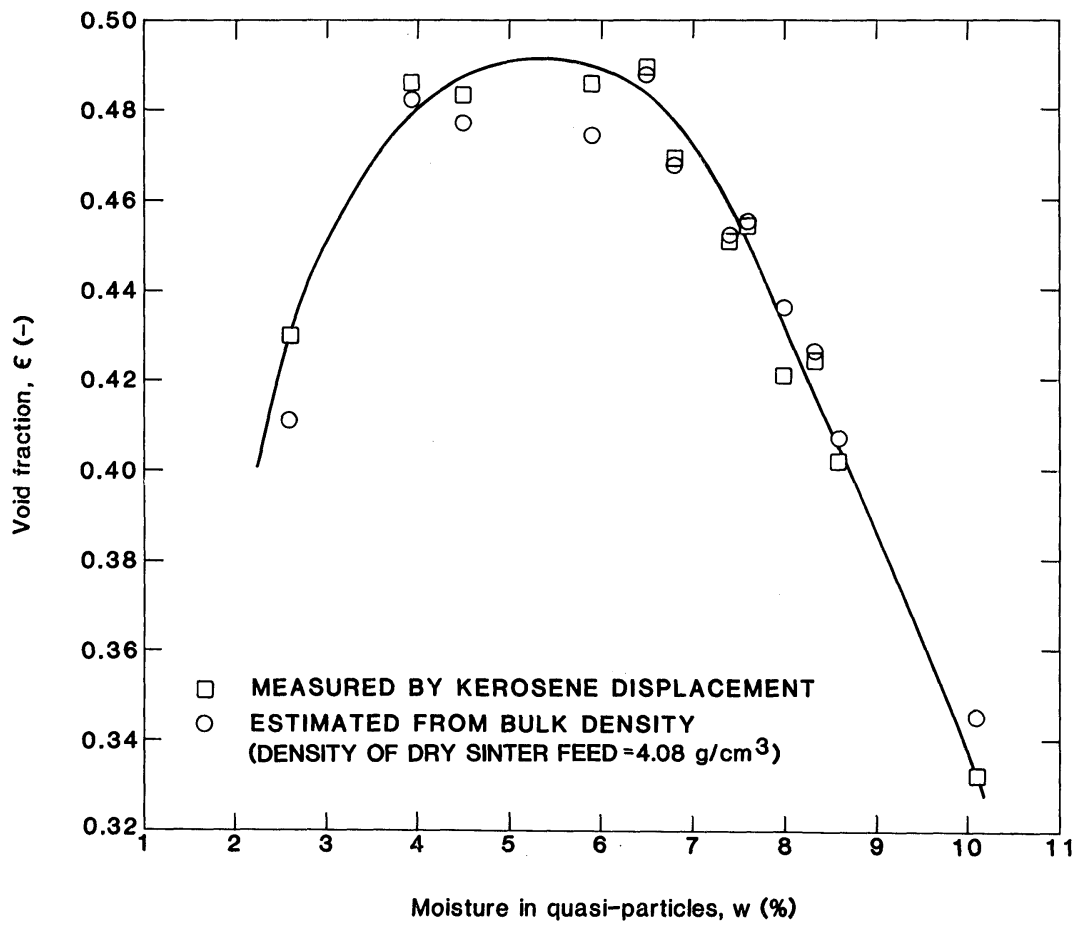

Fig. 2.

The variation of the bed void fraction with moisture content of a granulated iron ore sinter feed. 
The void fractions of mixes prepared in the large mixer and granulating drum may be compared with those of mixes prepared in the laboratory mixer. The value of 0.45 at $5.52 \%$ moisture (Table 1) is well below the value expected from Fig. 2 (viz. about 0.49 ) whereas the value of 0.46 at $6.98 \%$ moisture is within the experimental scatter of points in Fig. 2. Each value for the large mixes is an average of five tests and is considered to be reliable. Therefore, the variation of void fraction values at $5.52 \%$ moisture is due to the different granulating capabilities of the pilot-scale and laboratory mixers.

For some of the tests a second representative subsample of moist sinter mix was frozen in liquid nitrogen, as described previously, ${ }^{1)}$ and screened using a laboratory sieve shaker to obtain the size distribution of the quasi-particles. The results are presented in Fig. 3 and show that the mean quasi-particle diameter increases but the spread of the quasi-particle sizes decreases (i.e., the size distribution narrows) as the amount of water for granulation is increased.

\section{Discussion}

In the calculation of void fraction using Eq. (2) and (3) the value of $\rho_{0}$ was assumed such that a satisfactory fit was obtained at one point. To check this value, the true densities of the raw materials (i.e., the densities of the materials after grinding to destroy their internal porosity) were determined experimentally and the true density of the dry mix was calculated using the relation:

$$
\rho_{0}=\frac{100}{\frac{\% \text { ore }}{\rho_{\text {ore }}}+\frac{\% \text { sinter }}{\rho_{\text {sinter }}}+\frac{\% \text { limestone }}{\rho_{\text {limestone }}}+\frac{\% \text { coke }}{\rho_{\text {coke }}}}
$$

where, $\%$ : the mass percent in the dry mix

$\rho:$ the true densities of the components of the mix.
Using the data in Table 3 a value of $4.03 \mathrm{~g} / \mathrm{cm}^{3}$ is obtained. This compares favourably with the assumed value of $4.08 \mathrm{~g} / \mathrm{cm}^{3}$. Values of void fraction calculated using $\rho_{0}=4.03 \mathrm{~g} / \mathrm{cm}^{3}$ in Eq. (3) are shown in Table 2; they are not appreciably different from those found using $\rho_{0}=4.08 \mathrm{~g} / \mathrm{cm}^{3}$.

The agreement between the experimentally measured void fraction values and those obtained by calculation from the bulk density of the mix suggests that the assumptions made in deriving Eq. (3) are correct for the ore type investigated, viz.:

(1) All pores within the grains making up the quasi-particles are filled with water.

(2) All pores between the grains making up the quasi-particles are filled with water.

When different sized spheres are mixed, the void fraction of a bed is lower than for a bed of uniformly sized spheres with the same degree of packing ${ }^{8)}$ and the initial rise of the void fraction $v s$. moisture content curve (Fig. 2) is due probably to the narrowing of the size distribution of the granulated material as the moisture used for granulation is increased (Fig. 3). Above about $5.3 \%$ moisture the void fraction of the granulated sinter feed falls rapidly (Fig. 2). This occurs even though the size distribution of the quasiparticles continues to narrow (Fig. 3). The explanation for the decrease in void fraction appears to be

Table 3. Mass percent and true densities of the raw materials.

\begin{tabular}{l|cc}
\hline & $\begin{array}{c}\text { Mass percent } \\
(\%)\end{array}$ & $\begin{array}{c}\text { Density } \\
\left(\mathrm{g} / \mathrm{cm}^{3}\right)\end{array}$ \\
\hline Ore fines & 60.2 & 4.7 \\
Return sinter & 22.2 & 4.5 \\
Limestone & 13.5 & 2.7 \\
Coke & 4.1 & 2.0 \\
& 100.0 &
\end{tabular}

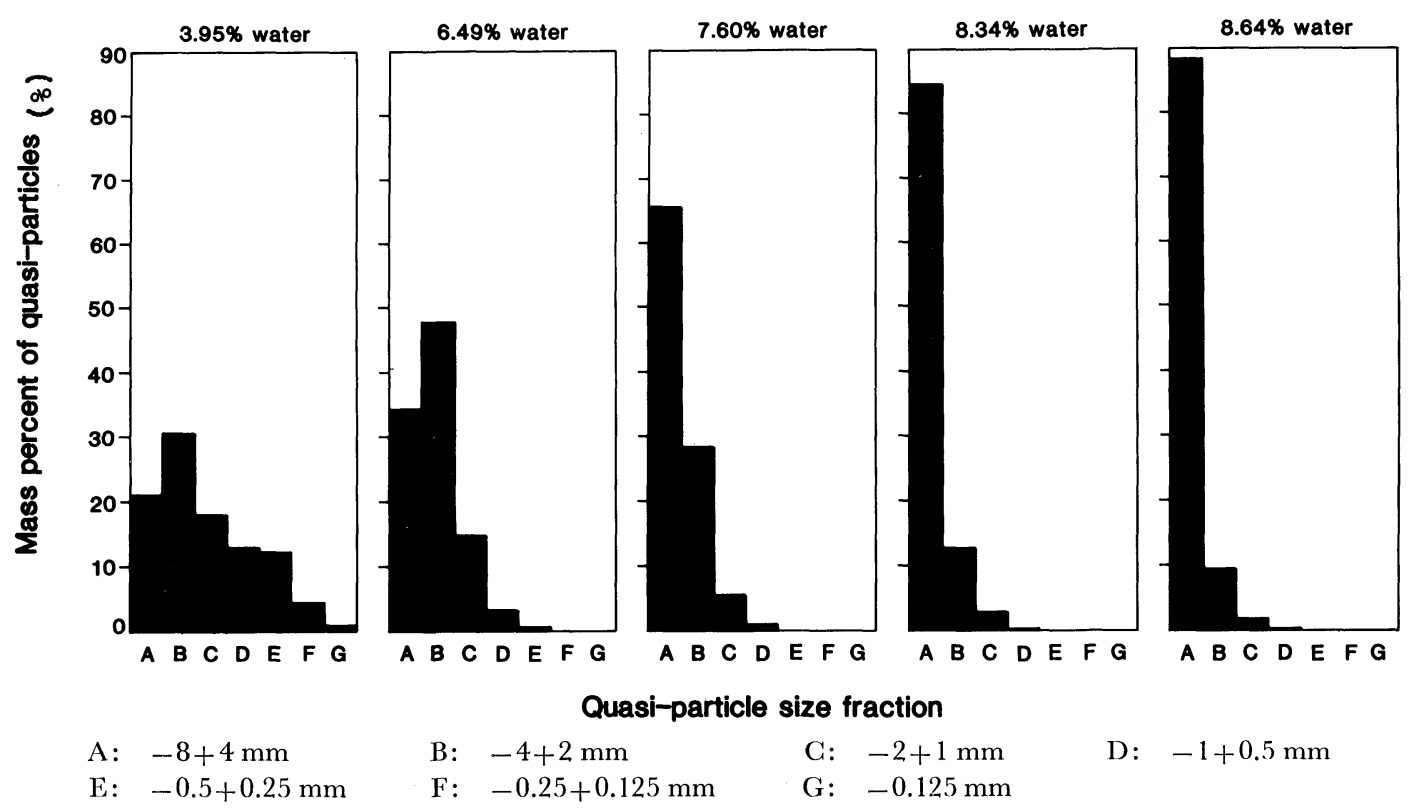

Fig. 3. The effect of moisture content on the size distribution of quasi-particles. 
that the quasi-particles slump when packed to form a bed due to weakening by an excessive amount of water above about $5.3 \%$.

\section{Conclusions}

(1) The void fraction of a bed of granulated iron ore sinter feed can be measured by filling the void space with kerosene after removing the air by evacuating the container to at least $84 \mathrm{kPa}$.

(2) For the iron ore type investigated, the bed void fraction initially rises as the amount of water used for granulation increases. This is due probably to a narrowing of the quasi-particle size distribution due to the granulation process. Maximum bed void fraction of 0.49 occurs at $5.3 \%$ moisture. Further addition of water during granulation results in a lowering of the bed void fraction due, most likely, to slumping of the quasi-particles when they are packed to form a bed.

(3) The observed trend of void fraction with moisture content was confirmed independently by bulk density measurements.

(4) Matching of the void fractions determined by kerosene displacement and by bulk density measurement required a density of the dry feed of $4.08 \mathrm{~g} / \mathrm{cm}^{3}$. This value agrees well with the value estimated from the densities of the raw materials and implies that for the sinter feed studied all internal porosity of the granules is filled with water.

\section{Acknowledgements}

This paper is published by permission of the Broken Hill Proprietary Co., Ltd.

\section{REFERENCES}

1) W. J. Rankin, P. W. Roller and R. J. Batterham: Proc. Joint Symposium of Iron Steel Inst. Japan and Austral. Inst. Mining Met., ISIJ, Tokyo, (1983), 13-28.

2) E. W. Voice and R. Wild: JISI, 183 (1956), 404-410.

3) E. W. Voice and R. Wild: Iron and Coal Trades Review, 175 (1957), 841-850.

4) E. W. Voice and R. Wild: Blast-Furn., Coke Oven, \& Raw
Materials Proc., AIME, 16 (1957), 121-146.

5) E. W. Voice and R. Wild: Sintering Symposium, Austral. Inst. Mining Met., (1958), 21-46.

6) S. Ergun: Chem. Eng. Prog., 48 (1952), 89-94.

7) W. J. Rankin, P. W. Roller and R.J. Batterham: Minerals and Metallurgical Processing, 2 (1985), 53-59.

8) G. H. Geiger and D. R. Poirier: Transport Phenomena in Metallurgy, Addison-Wesley Press, Mass., (1973), 100-102.

\section{Appendix}

The Density of Moist Quasi-particles of Sinter Feed

Consider $100 \mathrm{~g}$ of moist, granulated sinter feed.

Mass of the dry quasi-particles $=100-w \mathrm{~g}$

where, $w$ : the percent water on a moist basis.

Volume of solids in the quasi-particles

$$
=\frac{100-w}{\rho_{0}} \mathrm{~cm}^{3}
$$

where, $\rho_{0}$ : the density of the dry solids $\left(\mathrm{g} / \mathrm{cm}^{3}\right)$ not including their internal porosity.

Volume of water in the quasi-particles $=\frac{w}{\rho_{w}} \mathrm{~cm}^{3}$ where, $\rho_{w}$ : the density of water $\left(\mathrm{g} / \mathrm{cm}^{3}\right)$.

Volume of the moist quasi-particles = volume of solids + volume of pores in grains + volume of pores between grains

If it is assumed that the pores within grains and the pores between grains in the quasi-particles are completely filled with water, then

Volume of the moist quasi-particles

$$
=\frac{100-w}{\rho_{0}}+\frac{w}{\rho_{w}} \mathrm{~cm}^{3}
$$

and

Density of the moist quasi-particles

$$
=\frac{100}{\frac{100-w}{\rho_{0}}+\frac{w}{\rho_{w}}} \mathrm{~g} / \mathrm{cm}^{3}
$$

